\title{
Bullying Involvement and Empathy: Child and Target Characteristics
}

Tirza H. J. van Noorden ${ }^{1}$, Antonius H. N. Cillessen ${ }^{1}$, Gerbert J. T. Haselager ${ }^{1}$, Tessa A. M. Lansu ${ }^{1}$ and William M. Bukowski ${ }^{2}$

${ }^{I}$ Radboud University

${ }^{2}$ Concordia University

\begin{abstract}
This study investigated how the bullying involvement of a child and a target peer are related to empathy. The role of gender was also considered. We hypothesized that empathy primarily varies depending on the bullying role of the target peer. Participants were 264 7-12-year-old children ( $M_{\text {age }}=10.02, S D=1.00 ; 50 \%$ girls) from 33 classrooms who had been selected based on their bullying involvement (bully, victim, bully/victim, noninvolved) in the classroom. Participants completed a cognitive and affective empathy measure for each selected target classmate. We found no differences in cognitive and affective empathy for all targets combined based on children's own bullying involvement. However, when incorporating the targets' bullying involvement, bullies, victims, and bully/victims showed less empathy for each other than for noninvolved peers. Noninvolved children did not differentiate between bullies, victims and bully/victims. Girls reported more cognitive and affective empathy for girls than boys, whereas boys did not differentiate between girls and boys. The results indicated that children's empathy for peers depends primarily on the characteristics of the peer, such as the peer's bullying role and gender.
\end{abstract}

Keywords: bullying involvement; empathy; child characteristics; target characteristics; gender

Bullying is typically defined as a subtype of aggressive behavior in which an individual or group intentionally and repeatedly causes harm to a relatively powerless person over time (Olweus, 2010; Salmivalli, 2010; Salmivalli \& Peets, 2009). Victimization is defined as the experience of being the target of bullying. Bullying has received increased scientific and public attention internationally due to its high prevalence (e.g., Due et al., 2005) and its detrimental consequences for victims (for reviews, see, Arseneault, Bowes, \& Shakoor, 2010; Hawker \& Boulton, 2000; Isaacs, Card, \& Hodges, 2001; Reijntjes, Kamphuis, Prinzie, \& Telch, 2010; Troop-

Correspondence should be addressed to Tirza H. J. van Noorden, Behavioural Science Institute, Radboud University, P.O. Box 9104, 6500 HE Nijmegen, The Netherlands. Email: t.vannoorden@psych.ru.nl 
Gordon, Rudolph, Sugimura, \& Little, 2015) as well as for bullies (for reviews, see, Stassen Berger, 2007; Ttofi, Farrington, \& Lösel, 2012; Ttofi, Farrington, Lösel, \& Loeber, 2011). Prevention and intervention programs for bullying often include empathy training (see, for an overview, Farrington \& Ttofi, 2009). In line with a large body of research, these programs typically treat empathy as a dispositional trait or skill. However, empathy is directed at another person and the identity of this person (the 'target') may influence how much empathy one has for her or him. For example, people may have more empathy for a loved one than a stranger. In the context of bullying, children's empathy may depend on a target peer's bullying involvement. For example, children may have more empathy for a victim than a bully, but this may also depend on whether they themselves are victims or bullies. Therefore, the goal of this study was to extend existing knowledge on bullying involvement and empathy by focusing on the bullying role of the peer at whom children's empathy is directed, while also taking children's own bullying role into account. The role of gender was also considered.

\section{Bullying Involvement and Empathy}

A recent review by van Noorden, Haselager, Cillessen, and Bukowski (2015) revealed distinct associations of bullying and victimization with affective and cognitive empathy. Affective empathy is the ability to experience another person's emotions (e.g., Mehrabian \& Epstein, 1972), whereas cognitive empathy is the ability to understand another person's emotions (e.g., Hogan, 1969). In the review, bullying was found to be negatively associated with affective empathy. The association of bullying with cognitive empathy was mixed, with some studies finding a negative association and others indicating no association. This suggests that children who bully are not necessarily incapable of understanding others' feelings, but appear to experience others' feelings to a lesser extent. In addition, victimization was observed to be negatively associated with cognitive empathy but not with affective empathy, suggesting that victimized children are just as capable as nonvictimized children to experience what others feel, but report more difficulty understanding in others' feelings.

In addition to studies using continuous measures of bullying and victimization, a few studies have examined group differences in cognitive and affective empathy to directly compare children involved in bullying and/or victimization. Group comparisons between bullies, victims, bully/victims (who bully others and are victimized themselves), and noninvolved children (neither bully nor victim) were less conclusive (van Noorden et al., 2015). In one study bullies reported less affective empathy than was reported by victims, and bully/victims reported less affective empathy than was reported by victims and by noninvolved peers (Raskauskas, Gregory, Harvey, Rifshana, \& Evans, 2010). In another study victims reported more cognitive empathy than was reported by noninvolved peers, whereas victims did not differ from bullies and bully/victims (Williford, Boulton, \& Jenson, 2014). Other studies found no group differences in affective or cognitive empathy (Espelage, Mebane, \& Adams, 2004; Park, 2013; Warden \& Mackinnon, 2003).

\section{Target Empathy and Bullying Involvement}

The studies reviewed above focused on the association between children's own bullying involvement and their ability to have empathy for others. However, 
empathy - as the understanding and experience of another person's emotions - by definition implies an empathy target. In spite of this, the empathy measures of previous studies included an unsystematic and wide variety of possible empathy targets, including friends (e.g., 'It is hard for me to understand when my friends are sad' in the Basic Empathy Scale; Jolliffe \& Farrington, 2006), classmates (e.g., 'When a classmate is sad because she/he does not have someone to be with, do you feel bad?'; Chaux, Castro, Daza, Díaz, \& Hurtado, 2004), loved ones ('When somebody I care about is sad, I feel sad too' in the How I Feel in Different Situations scale; Bonino, Lo Coco, \& Tani, 1998), peers ('When I see other adolescents who feel bad, I empathize with them'; Zhou, Valiente, \& Eisenberg, 2003), people who are worse off ('I often have tender, concerned feelings for people less fortunate than me' in the Interpersonal Reactivity Index; Davis, 1980, 1983), strangers ('It makes me sad to see a lonely stranger in a group' in the Questionnaire Measure of Emotional Empathy; Mehrabian \& Epstein, 1972), or simply others in general ('I am not really interested in how other people feel' in the Toronto Empathy Questinonaire; Spreng, McKinnon, Mar, \& Levine, 2009). Sometimes the target was even an animal (e.g., 'I get upset when I see an animal being hurt' in the Index of Empathy for Children and Adolescents [IECA]; Bryant, 1982), a situation (e.g., "Emergency situations make me feel worried and upset" in the Feeling and Thinking Instrument; Garton \& Gringart, 2005), or a television scene (e.g., 'It often makes me distressed when I see something sad on TV' in the empathic responsiveness questionnaire [ERQ]; Olweus \& Endresen, 1998).

Because the dependent variables derived from these empathy measures were composite scores collapsed across such varying empathy target categories, the influence of the identity of the target on the association between bullying involvement and empathy remains unclear. However, previous research has shown that people do take target characteristics into account in emotion-related processes. For example, it was easier to accurately infer the emotions and feelings of friends than of strangers (Stinson \& Ickes, 1992). Or, another person's negative emotions due to social exclusion were shared more when the excluded person was a friend than a stranger (Meyer et al., 2013).

\section{Gender of the Empathy Target and Bullying Involvement}

In addition to familiarity with the other person, as in the last two examples, empathy also has been found to be influenced by a target's gender. Feshbach and Roe (1968) demonstrated that six- to seven-year-old children showed more affective empathy toward same-sex peers than toward other-sex peers. Bryant (1982) extended this by showing that boys' affective empathy for boys decreased across Grades 1, 4 and 7, whereas girls' affective empathy for girls increased over this same period. Averaging across grades, boys did not differentiate between boy and girl targets, whereas girls showed more affective empathy for girl than boy targets. In a sample of 13-16-year-olds, Olweus and Endresen (1998) found the opposite: the difference in affective empathy toward girl and boy targets increased with age for boys, but decreased for girls. All three studies were conducted with measures of affective empathy only, leaving differences in cognitive empathy for boy and girl targets unexplored.

Taking the bullying involvement of the child and the gender of both the child and target into account, Endresen and Olweus (2001) revealed that the gender of 
the target plays a role in the association between bullying and empathy. They found that bullying and empathy were negatively associated for boys but not for (younger) girls when the target was a boy, whereas bullying and empathy were negatively associated for girls but not for boys when the target was a girl. Despite these findings, later studies on bullying involvement using empathy measures that distinguished between boy and girl targets, such as the IECA (Bryant, 1982) and the ERQ (Olweus \& Endresen, 1998), combined the empathy scores toward both genders into an overall affective empathy score ignoring the empathy target's gender (Barchia \& Bussey, 2011; Cappadocia, Pepler, Cummings, \& Craig, 2012; Correia \& Dalbert, 2008; Nickerson \& Mele-Taylor, 2014; Nickerson, Mele, \& Princiotta, 2008; Park, 2013; Raskauskas et al., 2010; Warden \& Mackinnon, 2003; Woods, Wolke, Nowicki, \& Hall, 2009).

\section{Present Study}

This study examined the effects of children's bullying involvement and gender on empathy by considering the bullying role and gender of both the participant (the empathizing children) and the target (the objects of empathy). Whereas previous research on bullying and empathy focused on a broad range of targets, this study focuses on specific familiar peers (classmates). We first investigated whether children's empathy for a specific classmate depended on children's own bullying involvement. That is, we tested whether bullies, victims, bully/victims, and noninvolved children differed in cognitive and affective empathy for these specific peers. Because previous research on this association yielded inconsistent results (see van Noorden et al., 2015), this test was exploratory. We did not expect an interaction between the bullying role and gender of the empathizing children as few gender differences have been found in the association between bullying involvement and empathy (van Noorden et al.).

Previous research indicates that emotion-related processes depend on target characteristics (Meyer et al., 2013; Stinson \& Ickes, 1992). Therefore, we hypothesized that the bullying role of the target plays a role in how much empathy children feel for him or her. Furthermore, we expected that the effect of target bullying role might depend on the empathizer's own bullying role. Thus, we tested whether bullies, victims, bully/victims, and noninvolved children differed in their cognitive and affective empathy for other bullies, victims, bully/victims, and noninvolved children. Because denying oneself empathy for specific others may be a way to prevent negative emotions after aggressing against them, we expected bullies to have less empathy for victims and bully/victims than for noninvolved children. We hypothesized that victims would have less empathy for bullies and bully/victims than noninvolved children, because victims might be less likely to understand and experience the emotions of children who are able to harm other children. Hypotheses regarding bully/victims were exploratory. On the one hand bully/victims may have less empathy for bullies and victims than for noninvolved children. They may show less empathy toward victims in order to feel less negative about their own bullying behavior; they may show less empathy toward bullies because these bullies may have hurt them, and they do not want to be emotionally connected to their bullies. On the other hand, it is also possible that bully/victims do not differentiate between bullies, victims, and noninvolved peers - or may even have more empathy for bullies and victims than for noninvolved peers-based on having been shared 
experiences in the position of a bully as well as a victim, making it easier to relate to both groups of peers. Whether noninvolved children distinguished between bullies, victims, and bully/victims was tested exploratively.

We explored whether these effects were further qualified by the gender of the child and the target. As our participants were 7-12-year-old children, based on Bryant (1982) we expected that girls would have more cognitive and affective empathy for girls, but that boys would not differentiate between girls and boys. Because only one boy and one girl were included in each bullying role, empathy towards one's own role was not investigated. Based on distinct associations with bullying involvement (van Noorden et al., 2015), cognitive and affective empathy were considered separately throughout the study.

\section{Method}

This study consisted of two phases and was part of a larger project (van Noorden, Bukowski, Haselager, Lansu, \& Cillessen, 2016; van Noorden, Haselager, Cillessen, \& Bukowski, 2014; van Noorden, Haselager, Lansu, Cillessen, \& Bukowski, 2015). In Phase 1, peer nomination data for bullying and victimization were collected in elementary school classrooms. Based on nominations received, eight children from each classroom were invited to participate in Phase 2 in which cognitive and affective empathy toward specific classmates was measured.

\section{Phase 1: Bullying and Victimization}

Participants. For Phase 1838 children from 34 third- to fifth-grade classrooms of 11 elementary schools in The Netherlands were approached for participation. After school principals and teachers agreed to participate, parents were informed about both phases of the project in a letter. The study used a passive consent procedure, with the option to opt out of the study clearly presented in the information letter along with contact information of the researchers. Parents and children could object to participation at all times, whether it was prior, during, or after the data collection. This procedure was approved by the ethics committee of the first author's home institution. Parents of nine children objected to participation; no children objected themselves or stopped during the study. Due to the absence of 29 children, the final sample of Phase 1 consisted of 800 children (50.5\% boys) between 7 and 12 years $(M=10.01, S D=1.01)$, with 776 children $(97.0 \%)$ born in The Netherlands. Afterwards, all children received a small present and teachers received a $€ 10$ voucher as a token of our appreciation.

Procedure and Materials. Phase 1 took place in the participants' classrooms where they completed the measures simultaneously on individual $10^{\prime \prime}$ netbook computers. The children sat at separate desks with partitioning boards on both sides to prevent them from seeing each other's screens. The instructions indicated that we were interested in children's opinions and that there was no right or wrong answers. We told participants that their answers would be processed anonymously and handled confidentially. During the data collection, children were not allowed to talk to each other but could ask the researchers questions at any time.

During the introduction, definitions of bullying and victimization (cf., Olweus, 1996) were provided and discussed. As part of the data collection, children completed peer nominations for bullying ('Who in your classroom bullies others?') and 
Table 1. Mean Standardized (per Classroom) Bullying and Victimization Scores of Bullies, Victims, Bully/Victims and Noninvolved per Gender

\begin{tabular}{lrrrr}
\hline & \multicolumn{2}{c}{ Bullying } & \multicolumn{2}{c}{ Victimization } \\
\hline & Boys & Girls & Boys & Girls \\
\hline Bullies & 1.22 & 1.06 & -.19 & -.10 \\
Victims & -.17 & -.15 & 1.18 & 1.04 \\
Bully/Victims & .78 & .83 & .52 & .78 \\
Noninvolved & -.45 & -.47 & -.42 & -.43 \\
\hline
\end{tabular}

victimization ('Who in your classroom is bullied by others?'). They were asked these questions once for girl classmates and once for boy classmates. Children could answer by nominating from one up to all classmates whose names were presented on their screen in a random order.

\section{Phase 2: Target Empathy}

Participants. Based on the number of nominations received for bullying and victimization in Phase 1, eight children were selected from each classroom: a boy and girl bully (who scored in the highest quartile of bully nominations and lowest quartile of victim nominations), a boy and girl victim (who scored in lowest quartile of bully nominations and highest quartile of victim nominations), a boy and girl bully/ victim (who scored in the highest quartile of both bully and victim nominations), and a noninvolved boy and girl (who scored in the lowest quartile of both nominations). If more than one boy or girl met the criteria for a role, the child who fit the role the best (in terms of nominations received) was selected (see Table 1 for the mean standardized bullying and victimization scores for each bullying role per gender).

None of the selected children declined the invitation to participate in Phase 2. Data from one classroom were excluded due to disturbances during the Phase 2 data collection (two children had a meeting with a counselor and parents in the middle of the session, children from another classroom entered the room and started talking to the participants). This yielded a final sample of 264 children (132 boys and 132 girls) from 33 classrooms $\left(M_{\text {age }}=10.02, S D=1.00\right.$, range 7-12 years). Again, all children who participated in Phase 2 of the data collection received a small present as a token of our appreciation.

Procedure and materials. Phase 2 took place in a separate room at the participants' schools with all eight children completing the measures simultaneously on individual $10^{\prime \prime}$ netbook computers, separated by partition screens. The instructions stated that children were asked to answer questions about the other seven children in their group. We emphasized that the questions concerned personal opinions and that the answers would be processed anonymously and handled confidentially.

Cognitive empathy (four items) and affective empathy (four items) were measured toward each of the seven other children in the group. Items were selected from 
254 Tirza H. J. van Noorden, Antonius H. N. Cillessen, Gerbert J. T. Haselager et al.

Table 2. Cognitive and Affective Empathy Means and SDs (in Parentheses) of Bullies, Victims, Bully/Victims and Noninvolved for Each Other

\begin{tabular}{lccccc}
\hline \multicolumn{7}{c}{ Total } & Bullies & Victims & Bully/Victims & Noninvolved \\
\hline \multicolumn{7}{c}{} & & & & \\
\hline Cognitive Empathy & $56.1(18.8)$ & - & $54.6(21.0)$ & $52.3(21.7)$ & $61.3(21.0)$ \\
Bullies & $49.1(17.6)$ & $47.1(19.0)$ & - & $47.7(19.4)$ & $52.5(19.7)$ \\
Victims & $45.4(18.9)$ & $54.0(18.1)$ & $/$ & $60.3(17.7)$ \\
Bully/Victims & $55.6(16.0)$ & $52.4(17.4)$ & - \\
Noninvolved & $51.2(16.6)$ & $51.8(17.1)$ & $51.2(20.1)$ & $50.5(17.4)$ & \\
Affective Empathy & & & & & \\
Bullies & $26.1(20.3)$ & - & $24.3(20.4)$ & $23.6(22.6)$ & $30.3(23.9)$ \\
Victims & $24.0(17.3)$ & $23.0(17.8)$ & - & $22.1(18.2)$ & $27.0(19.3)$ \\
Bully/Victims & $26.2(19.6)$ & $24.6(20.1)$ & $23.5(20.6)$ & - & $30.4(21.8)$ \\
Noninvolved & $24.0(15.1)$ & $24.2(15.6)$ & $23.7(15.9)$ & $24.0(15.9)$ & - \\
\hline
\end{tabular}

the adapted version of the Basic Empathy Scale (BES; Jolliffe \& Farrington, 2006) - which was used in Phase 1 as part of the larger project (van Noorden et al., 2016) - and transformed to make the questionnaire target specific. For example, the cognitive item 'I can understand my friend's happiness when she/he does well at something' was transformed to 'I can understand Child $X$ 's happiness when she/he does well at something'; the affective item 'I become sad when I see other people crying' was transformed to 'I become sad when I see Child $X$ crying'. Participants indicated to what extent they agreed with each statement by clicking on a visual analogue scale - coded as a 100-point scale — with the anchors 'strongly disagree' [1] and 'strongly agree' [100]. The reliabilities (Cronbach's $\alpha$ ) of the scales for the four target roles ranged from .67 to .69 for cognitive empathy and from .76 to .83 for affective empathy.

\section{Results}

\section{Child Characteristics in Bullying and Empathy}

We first tested whether bullies, victims, bully/victims and noninvolved children differed in cognitive and affective empathy for classmates in general. To do so, we averaged children's cognitive and affective empathy scores across all targets with a bullying role other than their own (see the 'total' column in Table 2). We then conducted a 4 (Participant Bullying Role: Bully, Victim, Bully/Victim, NonInvolved) $\times$ 2 (Participant Gender: boy, girl) ANOVA on these generalized cognitive and affective empathy scores.

For cognitive empathy, the main effects of participant bullying involvement and participant gender and their interaction were not significant (all $F$ 's $<2.5$ ). Bullies, victims, bully/victims, and noninvolved children did not differ in their understanding of the emotions of classmates with a bullying role other than their own. Boys and girls did not differ in this understanding either. 
For affective empathy, there was no main effect of participant role $(F<1)$. Bullies, victims, bully/victims, and noninvolved children experienced the emotions of classmates with a bullying role other than their own to an equal extent. There was an effect of participant gender, $F(1,256)=6.78, p=.01, \eta_{p}^{2}=.03$. Girls reported more affective empathy for children with a bullying role other than their own $(M=27.9, S D=18.6)$ than boys $\operatorname{did}(M=22.2, S D=17.2)$. There was no participant bullying role by participant gender interaction $(F<1)$.

\section{Target Characteristics in Bullying and Empathy}

Second, we tested whether children within each type of bullying involvement differentiated in their cognitive and affective empathy between other children based on their role as bully, victim, bully/victim, or noninvolved child. The effects of participant gender and target gender were also examined. In this design, each participant represented a unique combination of bullying involvement and gender. Because empathy toward the self was not measured, there were no measures of empathy for a target with the same bullying involvement and gender as the child's own. Because these cells in the model were empty, it was impossible to test the research question with a single analysis. Therefore, for each type of bullying involvement a 3 (Target Bullying Role: the other three types of involvement) $\times 2$ (Participant Gender: boy, girl) $\times 2$ (Target Gender: girl, boy) mixed design ANOVA was conducted on the cognitive empathy and affective empathy scores with target bullying role and target gender as within-subject factors. The results of these eight tests are presented in Table 3. Below, we discuss the significant effects and interactions together with the corresponding post-hoc tests, conducted with Bonferroni corrections.

For bullies, the main effect of target bullying role was significant for both cognitive and affective empathy. Post hoc tests revealed that bullies had less empathy for victims and bully/victims than for noninvolved children (see Table 2). This effect of target bullying role was not further qualified by target gender or participant gender. There was also a significant main effect of target gender that was further qualified by the interaction with participant gender. Girl bullies had more cognitive and affective empathy for other girls $\left(M_{C}=61.7, S D_{C}=18.8 ; M_{A}=36.7\right.$, $\left.S D_{A}=25.4\right)$ than for boys $\left(M_{C}=48.8, S D_{C}=18.4 ; \quad M_{A}=23.2, S D_{A}=21.3\right)$, whereas boy bullies did not differentiate between boys and girls in terms of cognitive and affective empathy.

For victims, the main effect of target bullying role was significant for both cognitive and affective empathy. Victims had less empathy for bullies and bully/victims than for noninvolved children (see Table 2). Both effects were further qualified by target gender. With regard to girl targets, victims had less cognitive and affective empathy for bully/victims $\left(M_{C}=47.7, S D_{C}=23.8 ; M_{A}=23.0, S D_{A}=20.1\right)$ than for noninvolved girls $\left(M_{C}=54.8, S D_{C}=22.7 ; M_{A}=28.5, S D_{A}=22.3\right)$. With regard to boy targets, victims had less cognitive and affective empathy for bullies $\left(M_{C}=42.6\right.$, $\left.S D_{C}=21.8 ; M_{A}=18.6, S D_{A}=17.7\right)$ and less affective empathy for bully/victims $\left(M_{A}=21.1, S D_{A}=19.4\right)$ than for noninvolved boys $\left(M_{C}=50.3, S D_{C}=21.5\right.$; $\left.M_{A}=25.4, S D_{A}=20.3\right)$. The significant main effect of target gender was further qualified by participant gender for both forms of empathy. Girl victims had more empathy for girls $\left(M_{C}=56.6, S D_{C}=22.6 ; M_{A}=32.5, S D_{A}=20.4\right)$ than for boys $\left(M_{C}=45.8, S D_{C}=19.7 ; M_{A}=21.7, S D_{A}=16.4\right)$; boy victims did not differentiate between girls and boys in empathy. 


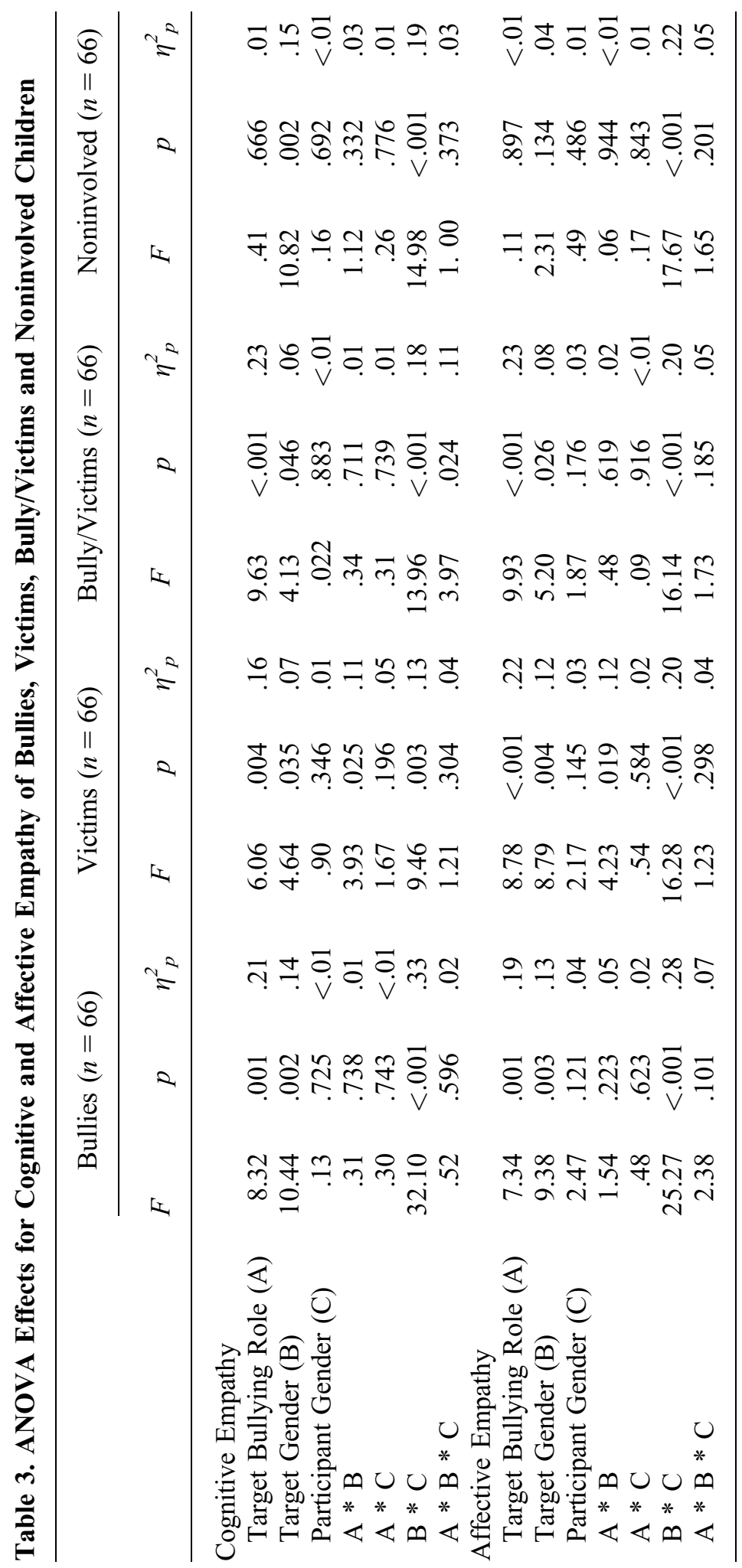


For bully/victims, the main effect of target bullying role was significant for cognitive and affective empathy. Bully/victims had less empathy for bullies and victims than for noninvolved children (see Table 2). For cognitive empathy, this effect was qualified by the interaction with target gender and participant gender. Post hoc tests revealed that girl bully/victims had less cognitive empathy for girl victims $\left(M_{C}=55.6, S D_{C}=19.7\right)$ than for noninvolved girls $\left(M_{C}=66.5, S D_{C}=16.1\right)$, whereas boy bully/victims had less cognitive empathy for girl bullies $\left(M_{C}=49.6\right.$, $\left.S D_{C}=25.5\right)$ than for noninvolved girls $\left(M_{C}=58.6, S D_{C}=25.1\right)$. Both girl and boy bully/victims had less cognitive empathy for boy bullies $\left(M_{C}=45.1, S D_{C}=21.3\right.$; $M_{C}=54.9, S D_{C}=22.7$, respectively) than for noninvolved boys $\left(M_{C}=51.6\right.$, $S D_{C}=19.5 ; M_{C}=64.3, S D_{C}=22.0$, respectively). The significant main effect of target gender was qualified by participant gender. Girl bully/victims had more empathy for girls $\left(M_{C}=60.8, S D_{C}=13.8 ; M_{A}=33.3, S D_{A}=21.7\right)$ than boys $\left(M_{C}=49.7, S D_{C}=15.3 ; M_{A}=25.6, S D_{A}=20.2\right)$, whereas boy bullies did not differentiate between girls and boys in empathy.

For noninvolved children, the main effect of target bullying role was not significant. Noninvolved children did not differentiate between bullies, victims, and bully/ victims in terms of cognitive or affective empathy (see Table 2). There were no significant interactions of target bullying role with target gender or participant gender. There was a significant main effect of target gender that was qualified by participant gender for cognitive and affective empathy. Post hoc analyses showed that noninvolved girls had more empathy for girls $\left(M_{C}=58.4, S D_{C}=19.1 ; M_{A}=29.5\right.$, $\left.S D_{A}=19.1\right)$ than for boys $\left(M_{C}=45.6, S D_{C}=17.8 ; M_{A}=21.1, S D_{A}=13.2\right)$; noninvolved boys did not differentiate between girls and boys in empathy.

\section{Discussion}

Empathy is often thought to be an individual trait or skill, but how much of empathy is actually based on the target? The goal of this study was to investigate the role of child and target characteristics in the association between bullying involvement and empathy. Concerning children's bullying involvement, we found no differences between bullies, victims, bully/victims and noninvolved children in cognitive and affective empathy for their selected classmates in general. But when information about the target's bullying involvement was included, effects were found. All children involved in bullying or victimization demonstrated less empathy for each other than for noninvolved children. The results supported the hypotheses and indicated that children do not empathize with all classroom peers to the same degree; rather, they differentiated between them based on their bullying involvement.

These findings show that bullies, victims, and bully/victims are capable of experiencing empathy to the same extent as noninvolved children and, therefore, that they have developed the empathy skills that are typical for their age. This contradicts the argument that bullies have a general deficiency in empathy that needs to be taught first in order to prevent bullying. Why teach a skill that already exists? Instead, we may need to focus on getting bullies - as well as victims and bully/victims - to empathize with specific peers for whom they initially have less empathy than for others.

In order to boost children's low levels of empathy for specific peers, it is important to know why they have less empathy for them. The reasons to empathize 
less with specific others involved in bullying may differ for bullies and victims. Bullies may have low levels of empathy for victims and bully/victims because this allows them to continue to aggress against them without negative emotions such as guilt or remorse. This does not apply to victims as they do not initiate the aggression. The process underlying victims' reduced empathy is more likely to be a difficulty or unwillingness to understand and experience the emotions of those who hurt others like them.

This study also demonstrated that having been in a peer's position does not guarantee high empathy for her or him. Specifically, bully/victims did not report high levels of empathy for bullies and for victims. To the contrary, they reported less empathy for bullies and victims than for noninvolved children. It is possible that the empathy that might be induced by having been in the same position as a peer is overruled by the negative attitude toward that peer. Previous research has shown that bully/victims stand out in terms of blame attribution, anger, and willingness to retaliate in response to an ambiguous aggressive situation (Camodeca, Goossens, Schuengel, \& Terwogt, 2003). It could be that bully/victims see the behavior of both victims and bullies in bullying situations as malicious and a threat, and therefore disengage from empathizing with them.

Noninvolved children did not differentiate between bullies, victims, and bully/ victims in cognitive or affective empathy. This lack of differentiation may indicate that children who do not bully and are not bullied have a certain level of empathy for all others to the same extent, meaning that their empathy is not dependent on the bullying involvement of the peer. It is possible that noninvolved children do not differentiate between others because they have no negative relationships with them. However, comparisons were made between bullies, victims, and bully/victims and not with other noninvolved children. Therefore, we cannot rule out the possibility that noninvolved children have less empathy for involved targets compared with noninvolved targets, just like involved children do. This could partly explain why noninvolved children did not have the highest levels of total cognitive and affective empathy (see Table 2).

The gender of the child and the target also played a role in the association between bullying involvement and empathy. For the effects of the gender of the participant and the target, we replicated Bryant's (1982) findings that girls reported more cognitive and affective empathy for other girls than for boys, whereas boys do not differentiate between girls and boys for either cognitive or affective empathy. In addition, victims reported less cognitive and affective empathy for peers who are bully/victims and for boy bullies than for noninvolved peers. Girl bully/victims reported less cognitive empathy for girl victims, whereas boy bully/victims reported less cognitive empathy for girl bullies than for noninvolved girls. Although both boys and girls are bully/victims, this does not necessarily mean that boy bully/victims and girl bully/victims are bullying the same classmates and are being victimized by the same classmates. That is, girl bully/victims may particularly bully girls but may not be bullied by other girls so much, whereas boy bully/victims may be bullied by girls rather than bullying girls themselves.

\section{Limitations and Future Research}

When interpreting the findings of this study we must keep in mind that our bullying involvement classification was based on classroom peer reports. Therefore, the 
findings of the present study represent group processes rather than dyadic processes, indicating the one's empathy for another person is associated with how this person is viewed by the group. By selecting specific bully-victim dyads, future research could investigate empathy toward children's own bullies and/or victims.

Other aspects of the relationship between child and target that we did not control for are friendship and popularity. Both may influence the empathy a child feels for a peer. In addition to these relational factors, future research may also focus on contextual factors of empathy. For example, a child might experience more empathy for a peer when the peer's distress is caused by a tragic loss than when it is caused by victimization.

Furthermore, in line with previous research on group differences in empathy (Espelage et al., 2004; Raskauskas et al., 2010; Williford et al., 2014), we identified the noninvolved group as children who were not involved in bullying or victimization. However, this group is not necessarily homogeneous. The noninvolved group may include outsiders who do nothing or are not even aware of the bullying, but may also include defenders who help victims (e.g., Salmivalli, Lagerspetz, Björkqvist, Österman, \& Kaukiainen, 1996). Previous research has established positive associations between defending and empathy, whereas the association between bystanding and empathy remains unclear (van Noorden et al., 2015). Therefore, subdividing the group of noninvolved children may provide additional insight in associations with empathy that may aid the prevention and intervention of bullying.

In the present investigation, empathy for peers in one's own bullying role could not be tested as only one girl and one boy were selected for each bullying role in each classroom. Target differences were therefore always tested between bullying roles other than the child's own. As mentioned, this may partly explain why noninvolved children did not have the highest levels of overall cognitive and affective empathy. This also may have contributed to the lack of differences between the bullying roles in their empathy toward their selected classmates in general. A larger study with two boys and girls from each bullying role technically would make it possible to test children's empathy toward peers in their own role. But this may not be an ideal solution, as given the prevalence of bullies, victims, and bully/victims as reported in previous research, it is not very likely that all classrooms actually have two boys and two girls who show the behavior associated with each bullying role. Such a design would increase variation in the consensus on who the bullies and the victims are. That is, the first ranked bully in one classroom may have been nominated by a much larger proportion of classroom peers than the first ranked bully in another classroom. To facilitate that at least one girl and one boy could be identified in the present study, we asked children to name at least one girl and one boy for the bullying and victimization items. This means that less extreme cases may have been identified, which may have made our group comparisons more conservative. This phenomenon would only be more extreme when using a design that requires four targets for each bullying role per classroom. Before making decisions about the optimal design for a new study, perhaps careful simulations should be conducted first to understand exactly how these processes might work and influence group comparisons.

Further, our cognitive empathy measures were somewhat less reliable than our affective empathy measures. The alphas of the empathy measure for the four target roles ranged from .67 to .69 for cognitive empathy and from .76 to .83 for affective 
empathy. Future studies may want to include additional items or other empathy measures to increase the reliability of the cognitive empathy measure.

Finally, this was a correlational study with a cross-sectional design. Although some directional effects are more likely than others, we cannot draw conclusions about causal relationships. Future longitudinal research may investigate developmental trajectories of children's empathy, while taking the bullying involvement and gender of both the child and the target into account.

\section{Conclusion}

This study demonstrated how the association between bullying involvement and empathy varies depending on characteristics of the child as well as the target. We often think that variations in empathy are due to individual differences, but the findings of the present study indicate that these variations are especially due to target differences. Specifically, bullies, victims, and bully/victims showed less empathy for each other than for noninvolved peers. This has implications for research on bullying and empathy that has so far primarily focused on child characteristics. Moreover, it has implications for bullying prevention and intervention programs that include training of empathy skills for bullies. Such programs may want to focus on reducing empathy differences between targets, thereby hopefully enhancing empathy toward those peers for whom bullies, victims, and bully/victims initially have low empathy.

\section{References}

Arseneault, L., Bowes, L., \& Shakoor, S. (2010). Bullying victimization in youths and mental health problems: 'Much ado about nothing'? Psychological Medicine, 40, 717-729. doi: 10.1017/S0033291709991383

Barchia, K., \& Bussey, K. (2011). Predictors of student defenders of peer aggression victims: Empathy and social cognitive factors. International Journal of Behavioral Development, 35, 289-297. doi: 10.1177/0165025410396746

Bonino, S., Lo Coco, A., \& Tani, F. (1998). Empatia: Processi di condivisione delle emozioni [Empathy: Processes of emotional sharing]. Florence: Giunti.

Bryant, K. B. (1982). An index of empathy for children and adolescents. Child Development, 53, 413-425. doi: 10.2307/1128984

Camodeca, M., Goossens, F. A., Schuengel, C., \& Terwogt, M. M. (2003). Links between social information processing in middle childhood and involvement in bullying. Aggressive Behavior, 29, 116-127. doi: 10.1002/ab.10043

Cappadocia, M. C., Pepler, D., Cummings, J. G., \& Craig, W. (2012). Individual motivations and characteristics associated with bystander intervention during bullying episodes among children and youth. Canadian Journal of School Psychology, 27, 201-216. doi: $10.1177 / 0829573512450567$

Chaux, E., Castro, L., Daza, J., Díaz, C., \& Hurtado, N. (2004). Empatía: Instrumento de autoreporte. Bogota: Universidad de los Andes.

Correia, I., \& Dalbert, C. (2008). School bullying: Belief in a personal just world of bullies, victims, and defenders. European Psychologist, 13, 248-254. doi: 10.1027/10169040.13.4.248

Davis, M. H. (1980). A multidimensional approach to individual differences in empathy. JSAS Catalog of Selected Documents in Psychology, 10, 85.

Davis, M. H. (1983). Measuring individual differences in empathy: Evidence for a multidimensional approach. Journal of Personality and Social Psychology, 44, 113-126. doi: 10.1037/0022-3514.44.1.113

Due, P., Holstein, B. E., Lynch, J., Diderichsen, F., Gabhain, S. N., Scheidt, P., et al. (2005). Bullying and symptoms among school-aged children: International comparative 
cross sectional study in 28 countries. The European Journal of Public Health, 15, 128-132. doi: 10.1093/eurpub/cki105

Endresen, I. M., \& Olweus, D. (2001). Self-reported empathy in Norwegian adolescents: Sex differences, age trends, and relationship to bullying. In A. C. Bohart \& D. J. Stipek (Eds.), Constructive \& destructive behavior: Implications for family, school, \& society (pp. 147-165). Washington, DC: American Psychological Association.

Espelage, D. L., Mebane, S. E., \& Adams, R. S. (2004). Empathy, caring, and bullying: Toward an understanding of complex associations. In D. L. Espelage \& S. M. Swearer (Eds.), Bullying in American schools: A social-ecological perspective on prevention and intervention (pp. 37-61). Mahwah, NJ: Lawrence Erlbaum.

Farrington, D. P., \& Ttofi, M. M. (2009). School-based programs to reduce bullying and victimization. Campbell Systematic Reviews, 6, 1-147. doi: 10.4073/csr.2009.6

Feshbach, N. D., \& Roe, K. (1968). Empathy in six-and seven-year-olds. Child Development, 39, 133-145. doi: 10.2307/1127365

Garton, A. F., \& Gringart, E. (2005). The development of a scale to measure empathy in 8-and 9-year old children. Australian Journal of Education and Developmental Psychology, 5, 17-25.

Hawker, D. S. J., \& Boulton, M. J. (2000). Twenty years' research on peer victimization and psychosocial maladjustment: A meta-analytic review of cross-sectional studies. Journal of Child Psychology and Psychiatry, 41, 441-455. doi: 10.1111/1469-7610.00629

Hogan, R. (1969). Development of an empathy scale. Journal of Consulting and Clinical Psychology, 33, 307-316. doi: 10.1037/h0027580

Isaacs, J., Card, N. A., \& Hodges, E. V. E. (2001). Victimization by peers in the school context. New York State Psychologist, 13, 21-24.

Jolliffe, D., \& Farrington, D. P. (2006). Development and validation of the Basic Empathy Scale. Journal of Adolescence, 29, 589-611. doi: 10.1016/j.adolescence.2005.08.010

Mehrabian, A., \& Epstein, N. (1972). A measure of emotional empathy. Journal of Personality, 40, 525-543. doi: 10.1111/j.1467-6494.1972.tb00078.x

Meyer, M. L., Masten, C. L., Ma, Y., Wang, C., Shi, Z., Eisenberger, N. I., et al. (2013). Empathy for the social suffering of friends and strangers recruits distinct patterns of brain activation. Social Cognitive and Affective Neuroscience, 8, 446-454. doi: 10.1093/scan/nss019

Nickerson, A. B., Mele, D., \& Princiotta, D. (2008). Attachment and empathy as predictors of roles as defenders or outsiders in bullying interactions. Journal of School Psychology, 46, 687-703. doi: 10.1016/j.jsp.2008.06.002

Nickerson, A. B., \& Mele-Taylor, D. (2014). Empathetic responsiveness, group norms, and prosocial affiliations in bullying roles. School Psychology Quarterly, 29, 99-109. doi: $10.1037 /$ spq0000052

Olweus, D. (1996). Bullying at school: Knowledge base and an effective intervention program. Annals of the New York Academy of Sciences, 794, 265-276. doi: 10.1111/j.17496632.1996.tb32527.x

Olweus, D. (2010). Understanding and researching bullying: Some critical issues. In S. R. Jimerson, S. M. Swearer, \& D. L. Espelage (Eds.), Handbook of bullying in schools. New York: Routhledge.

Olweus, D., \& Endresen, I. M. (1998). The importance of sex-of-stimulus object: Age trends and sex differences in empathic responsiveness. Social Development, 7, 370-388. doi: 10.1111/1467-9507.00073

Park, J. H. (2013). Differential correlates of bully/victim status and bystander roles of school violence with school adjustment in Korea. KEDI Journal of Educational Policy, Special Issue, 119-133.

Raskauskas, J. L., Gregory, J., Harvey, S. T., Rifshana, F., \& Evans, I. M. (2010). Bullying among primary school children in New Zealand: Relationships with prosocial behaviour and classroom climate. Educational Research, 52, 1-13. doi: 10.1080/00131881003588097

Reijntjes, A., Kamphuis, J. H., Prinzie, P., \& Telch, M. J. (2010). Peer victimization and internalizing problems in children: A meta-analysis of longitudinal studies. Child Abuse \& Neglect, 34, 244-252. doi: 10.1016/j.chiabu.2009.07.009

Salmivalli, C. (2010). Bullying and the peer group: A review. Aggression and Violent Behavior, 15, 112-120. doi: 10.1016/j.avb.2009.08.007

Salmivalli, C., Lagerspetz, K. M. J., Björkqvist, K., Österman, K., \& Kaukiainen, A. (1996). Bullying as a group process: Participant roles and their relations to social status within the 
group. Aggressive Behavior, 22, 1-15. doi: 10.1002/(sici)1098-2337(1996)22:1 < 1::aid$\mathrm{ab} 1>3.0 . \mathrm{co} ; 2-\mathrm{t}$

Salmivalli, C., \& Peets, K. (2009). Bullies, victims, and bully-victim relationships in middle childhood and early adolescence. In K. H. Rubin, W. M. Bukowski, \& B. Laursen (Eds.), Handbook of peer interactions, relationships, and groups (pp. 322-340). New York: Guilford.

Spreng, R. N., McKinnon, M. C., Mar, R. A., \& Levine, B. (2009). The Toronto Empathy Questionnaire: Scale development and initial validation of a factor-analytic solution to multiple empathy measures. Journal of Personality Assessment, 91, 62-71. doi: 10.1080/ 00223890802484381

Stassen Berger, K. (2007). Update on bullying at school: Science forgotten? Developmental Review, 27, 90-126. doi: 10.1016/j.dr.2006.08.002

Stinson, L., \& Ickes, W. (1992). Empathic accuracy in the interactions of male friends versus male strangers. Journal of Personality and Social Psychology, 62, 787-797. doi: 10.1037/0022-3514.62.5.787

Troop-Gordon, W., Rudolph, K. D., Sugimura, N., \& Little, T. D. (2015). Peer victimization in middle childhood impedes adaptive responses to stress: A pathway to depressive symptoms. Journal of Clinical Child \& Adolescent Psychology, 44, 432-445. doi: 10.1080/ 15374416.2014.891225

Ttofi, M. M., Farrington, D. P., \& Lösel, F. (2012). School bullying as a predictor of violence later in life: A systematic review and meta-analysis of prospective longitudinal studies. Aggression and Violent Behavior, 17, 405-418. doi: 10.1016/j.avb.2012.05.002

Ttofi, M. M., Farrington, D. P., Lösel, F., \& Loeber, R. (2011). The predictive efficiency of school bullying versus later offending: A systematic/meta-analytic review of longitudinal studies. Criminal Behaviour and Mental Health, 21, 80-89. doi: 10.1002/cbm.808

van Noorden, T. H. J., Bukowski, W. M., Haselager, G. J. T., Lansu, T. A. M., \& Cillessen, A. H. N. (2016). Disentangling the frequency and severity of bullying and victimization in the association with empathy. Social Development, 1, 176-192. doi: 10.1111/ sode. 12133

van Noorden, T. H. J., Haselager, G. J. T., Cillessen, A. H. N., \& Bukowski, W. M. (2014). Dehumanization in children: The link with moral disengagement in bullying and victimization. Aggressive Behavior, 40, 320-328. doi: 10.1002/ab.21522

van Noorden, T. H. J., Haselager, G. J. T., Cillessen, A. H. N., \& Bukowski, W. M. (2015). Empathy and involvement in bullying in children and adolescents: A systematic review. Journal of Youth and Adolescence, 44, 637-657. doi: 10.1007/s10964-014-0135-6

van Noorden, T. H. J., Haselager, G. J. T., Lansu, T. A. M., Cillessen, A. H. N., \& Bukowski, W. M. (2015). Attribution of human characteristics and bullying involvement in childhood:Distinguishing between targets. Aggressive Behaviour. Advance online publication. doi: 10.1002/ab.21634

Warden, D., \& Mackinnon, S. (2003). Prosocial children, bullies and victims: An investigation of their sociometric status, empathy and social problem-solving strategies. British Journal of Developmental Psychology, 21, 367-385.

Williford, A., Boulton, A. J., \& Jenson, J. M. (2014). Transitions between subclasses of bullying and victimization when entering middle school. Aggressive Behavior, 40, 24-41. doi: $10.1002 / \mathrm{ab} .21503$

Woods, S., Wolke, D., Nowicki, S., \& Hall, L. (2009). Emotion recognition abilities and empathy of victims of bullying. Child Abuse \& Neglect, 33, 307-311. doi: 10.1016/ j.chiabu.2008.11.002

Zhou, Q., Valiente, C., \& Eisenberg, N. (2003). Empathy and its measurement. In S. J. L. C. R. Snyder (Ed.), Positive psychological assessment: A handbook of models and measures (pp. 269-284). Washington, DC: American Psychological Association.

\section{Acknowledgments}

This work was part of project 'Empathy \& Bullying in Childhood' (file number: 431-09029) funded by the National Initiative Brain and Cognition (NIBC) of the Netherlands Organization for Scientific Research (NWO). The authors are grateful to the children, parents, and school administrators who made this research possible. 